\title{
Aktualisasi Pancasila Dalam Mendukung Pertumbuhan Ekonomi Nasional
}

Prof. Dr. Wimboh Santoso, S.E., MSc., Ph.D.

Otoritas Jasa Keuangan

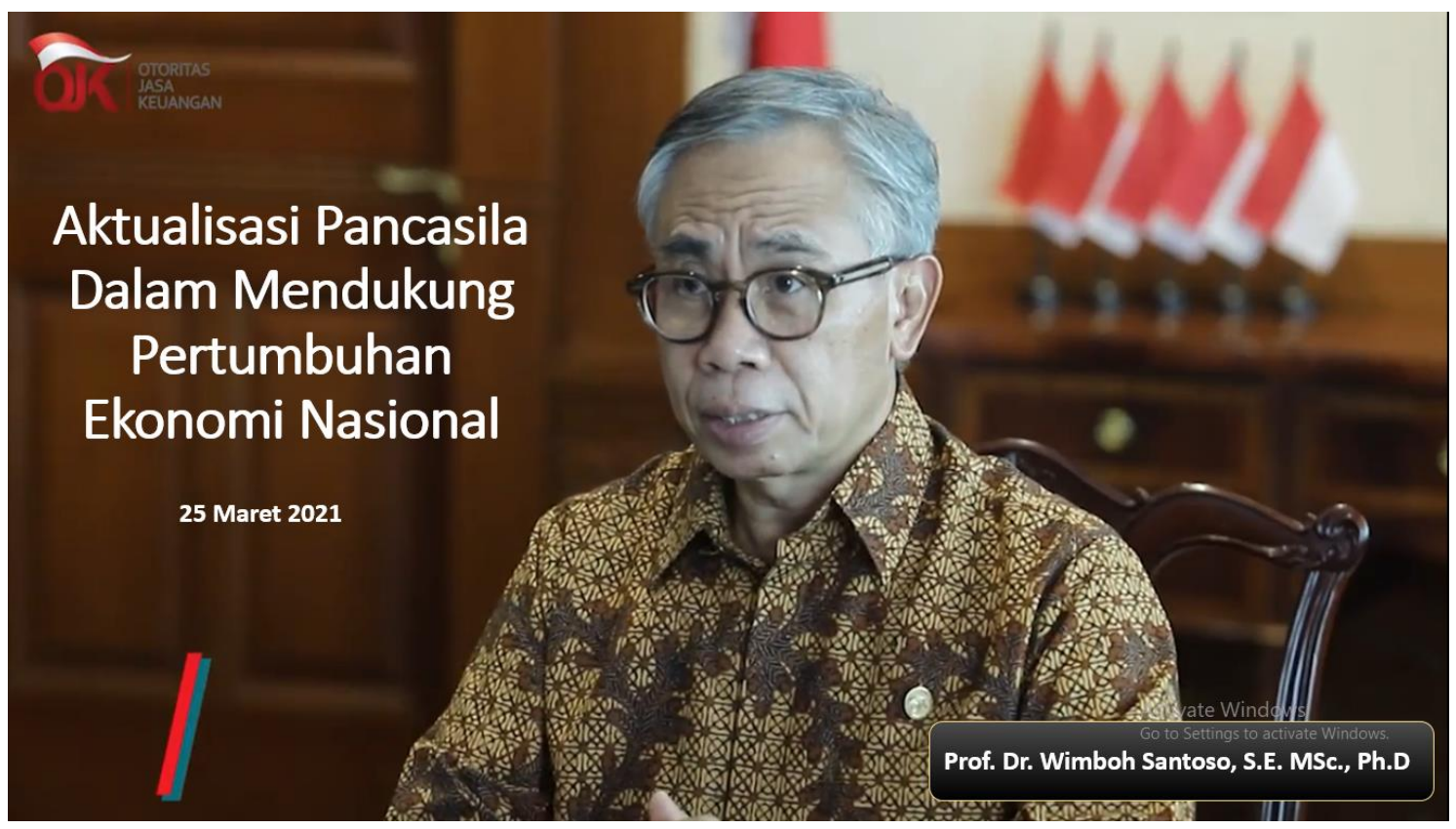

\section{Peranan Pancasila}

Sebuah Dasar Ideologi Negara Republik Indonesia
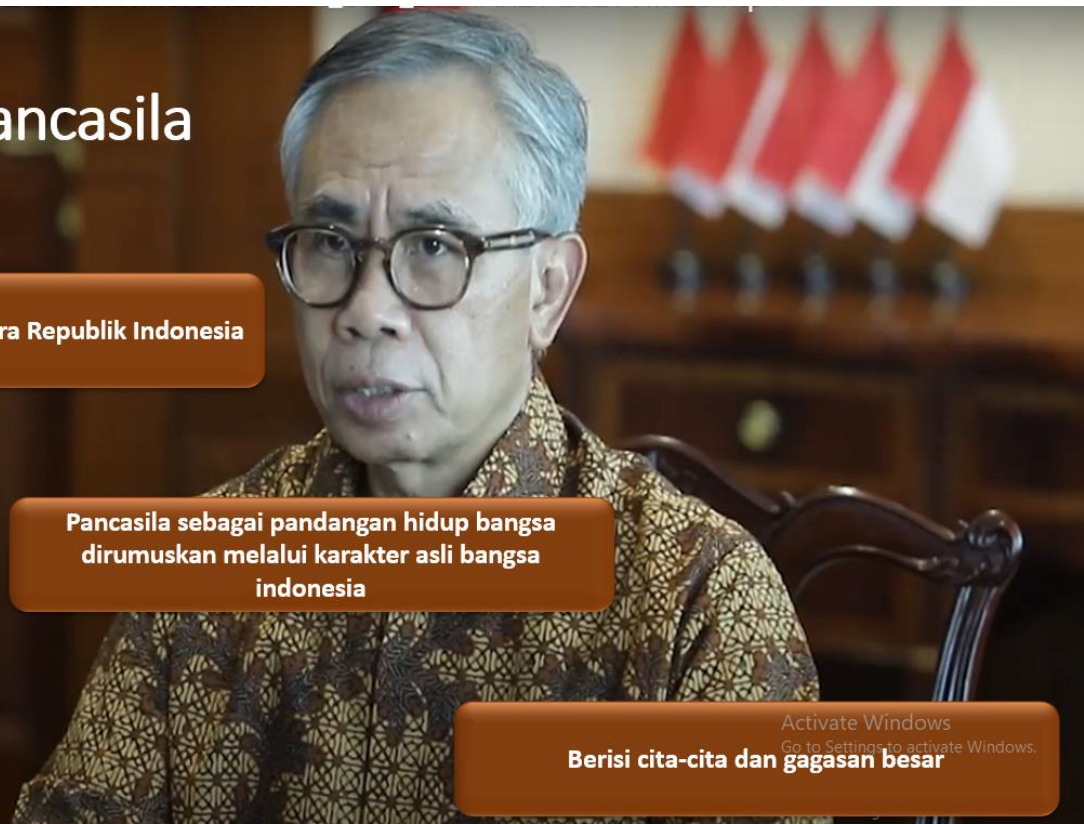


\section{Pancasila Sebagai Dasar Ideologi Negara Republik Indonesia}

Pancasila adalah bagian yang penting dari UUD 1945 menjadi landasan yang kuat bagi

1) Pembangunan Ekonomi plurentasi keadilan

2) Pemenuhan hak hak sosial rakyat,

3) Perlakuan dan kesempatan yang sama bagi seluruh rakyat Indonesia.

4) Pemerataan Pembangunan

5) Persatuan Bangsa

Khusus untuk pembangunan ekonomi, Pancasila sebagai dasar Negara menjadi sistem ekonomi yang disebut

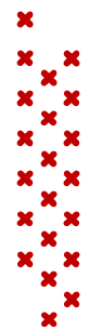
Ekonomi Pancasila. Sebagaimana dengan apa yang terdapat pada pasal 33 UUD 1945 setelah Amandemen tahun 2002 perekonomian nasional diselenggarakan dengan prinsip kebersamaan atas dasar :

Berkeadilan

Demokrasi

Ekonomi

Efisiensi
Menjaga keseimbangan kemajuan kesatuan ekonomi nasional

\section{Berkelanjutan}

Berwawasan lingkungan

Kemandirian

\section{TUJUAN EKONOMI}

PANCASILA

Ekonomi Pancasila memiliki tujuan mulia yaitu meningkatkan kesejahteraan masyarakat melalui pemerataan pendapatan dan pembangunan serta memajukan pertumbuhan ekonomi Indonesia dengan tetap mempertahankan stabilitas keuangan.

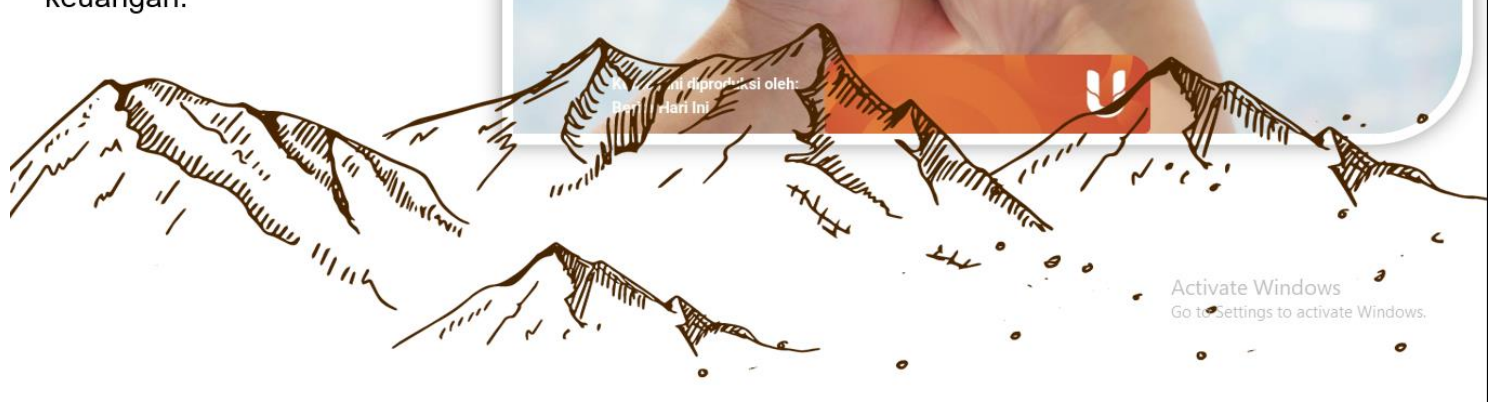




\section{ETERKAITAN DENGANO}

OJK dibentuk dengan tujuan yịng falas) dengan aktualisasi ekonomi

Pancasila, yaitu

1. Mewujudkan terselenggaran keuangan secara teratur adj: regnsparan dan countable

2. Mewujudkān sistena uug gem Xahg tumbuh secora berkelanjutan dan stabil-

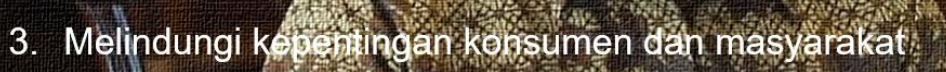

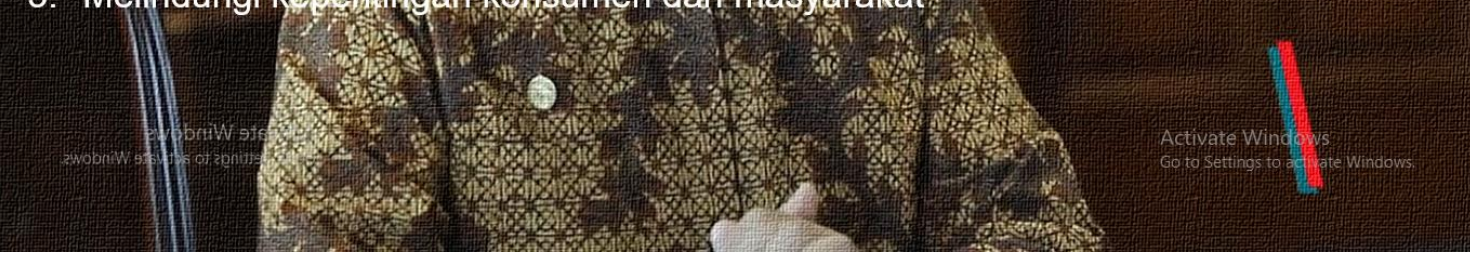

\section{Aktualisasi Ekonomi pada Setiap Sila Pancasila}

\section{SILA PERTAMA}

SILA KEDUA
SILA KETIGA
Penerapan dalam pelaksanaan pengawasan sektor keuangan sebagai bentuk tanggung jawab kepada Tuhan Yang Maha Kuasa dengan demikian dapat memajukan kepentingan dan kesejahteraan seluruh rakyat Indonesia

Kebijakan yang humanis atau perikemanusiaan melalui penyediaan akses pembiayaan yang seluas-luasnya kepada semua rakyat Indonesia dalam mengembangkan kualitas hidup individu dan masyarakat

Kebijakan yang mampu meningkatkan ketangguhan dan kedaulatan ekonomi nasional serta meningkatkan daya saing sektor jasa keuangan di kancah global dan regional di mana persatuan Indonesia menjadi pilar utama 

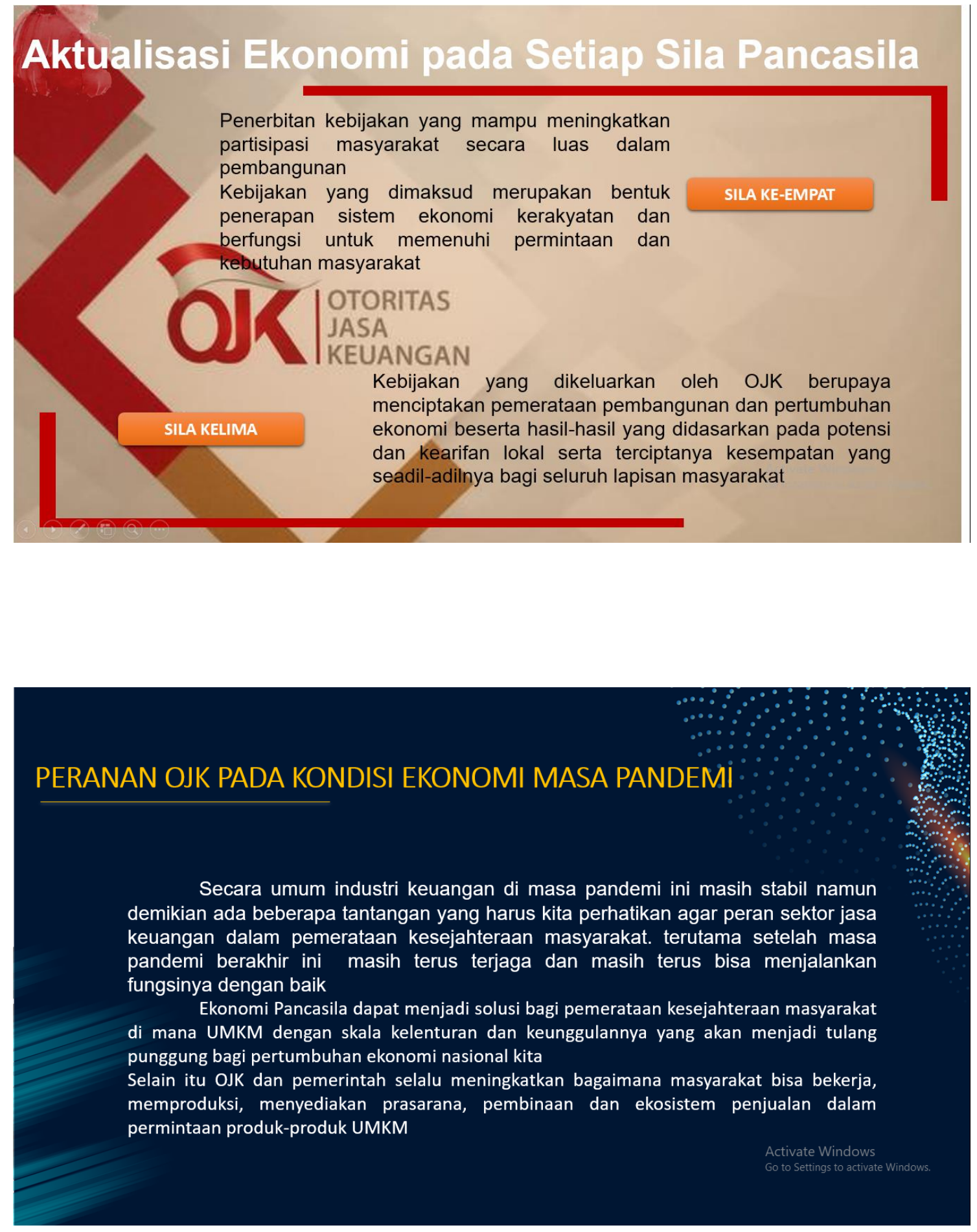


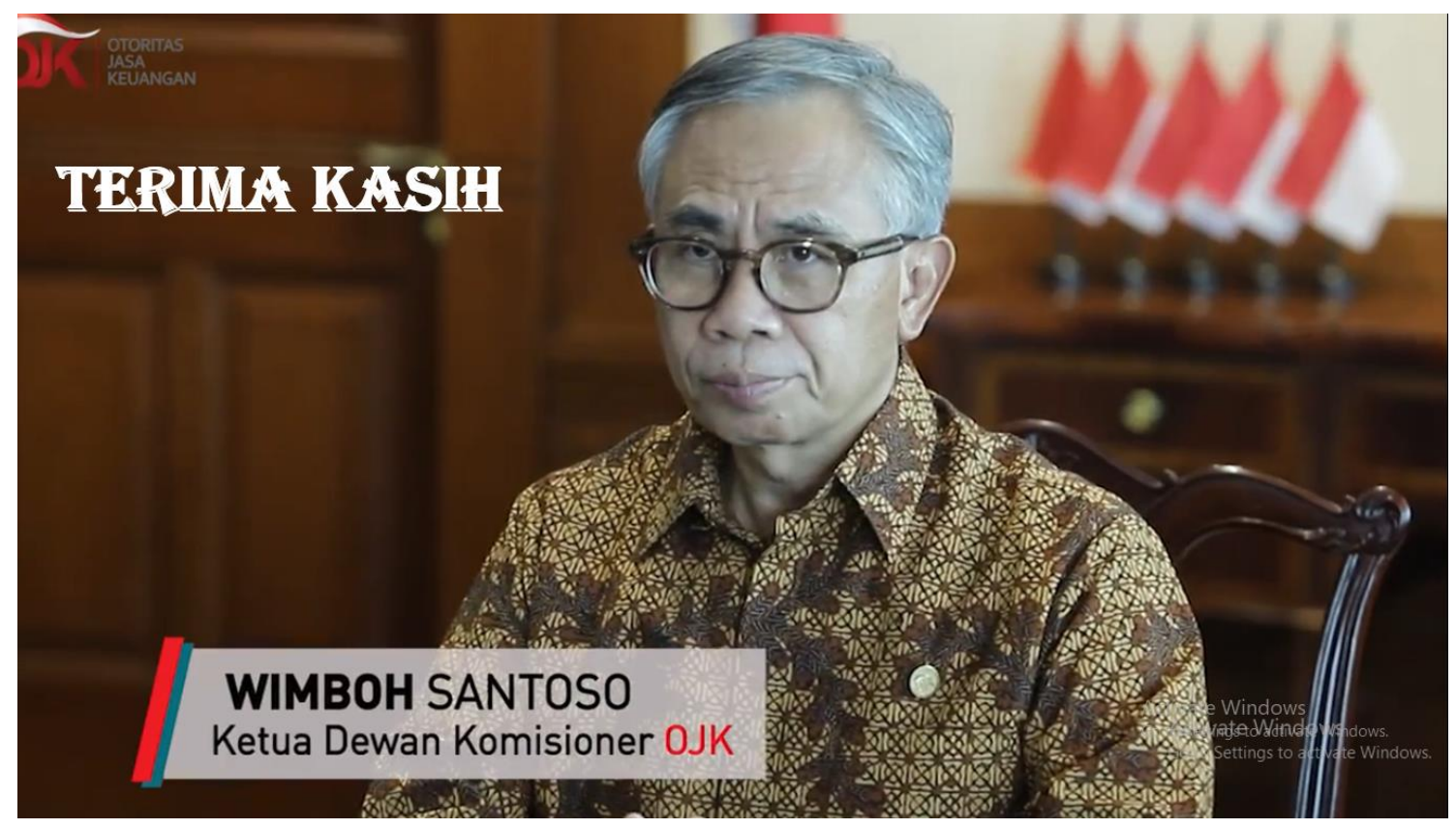

